Journal of Cancer and Tumor International
$5(4): \begin{gathered}1-9,2017 ; \text { Article no.JCTI.33231 } \\ \text { ISSN: } 2454-7360\end{gathered}$
SCIENCEDOMAIN international
WwW.SCiencedomain.org

\title{
Papanicoleau Smear Usage and Prevalence of Premalignant Cervical Lesion among Women Living with HIV Attending a Federal Teaching Hospital in South-West Nigeria: A Comparative Study
}

\section{Aishatu Omoragbon ${ }^{1}$, Olusegun Emmanuel Gabriel ${ }^{1 *}$, Olabode Muftau Shabi ${ }^{1}$, Oluwaserimi Adewumi Ajetunmobi ${ }^{1}$, Olayide Toyin Elegbede ${ }^{1}$, Segun Mathew Agboola ${ }^{1}$ and Adebara Idowu Oluwaseyi ${ }^{2}$}

${ }^{1}$ Department of Family Medicine, Federal Teaching Hospital, Ido-Ekiti, Ekiti State, Nigeria.
${ }^{2}$ Department of Obstetrics and Gynaecology, Federal Teaching Hospital, Ido-Ekiti, Ekiti State, Nigeria.

Authors' contributions

This work was carried out in collaboration between all authors. All authors read and approved the final manuscript.

Article Information

DOI: $10.9734 / \mathrm{JCTI} / 2017 / 33231$

Editor(s):

(1) William C. S. Cho, Queen Elizabeth Hospital, Hong Kong.

Reviewers:

(1) Agnieszka Korolczuk, Medical University, Lublin, Poland.

(2) Ouasmani Fatima, Ibn Tofail University, Kenitra, Morocco. Complete Peer review History: http://www.sciencedomain.org/review-history/19313

Original Research Article

Received $5^{\text {th }}$ April 2017 Accepted $12^{\text {th }}$ May 2017 Published $2^{\text {nd }}$ June 2017

\section{ABSTRACT}

Aim: Cancer of the cervix is the third most common cancer among women worldwide, and in Nigeria it is the second most common female cancer. Infection with the Human immunodeficiency virus (HIV) is associated with an increased risk of prevalent, incident and persistent squamous intraepithelial lesions (SILs) of the cervix. The aim was to determine the level of awareness of cervical cancer screening test and the development of premalignant cervical lesions among HIV positive women.

Study Design: A Hospital based comparative cross-sectional study.

Place and Duration of the Study: The study was carried out in the HIV clinic and general outpatient clinic of Federal Teaching Hospital Ido-ekiti, Ekiti state Nigeria. It was carried out from July to September 2015. 


\begin{abstract}
Methodology: The study was carried out among 65 HIV-positive and 65 HIV-negative women. Data were collected from the interviewees. Participants also had Pap smear. Data collected were analyzed using statistical package for social sciences version 19.

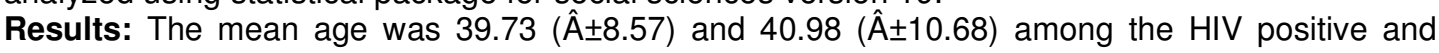
negative women respectively. Only $27.7 \%$ of the HIV-positive women compared to $56.9 \%$ of the HIV negative women had heard of cervical cancer with $\mathrm{P}=0.001$. The level of awareness of cervical cancer screening test was $15.4 \%$ and $50.8 \%$ among the HIV positive and negative women respectively $(P=0.001)$. The prevalence of premalignant cervical lesions among the study and control groups was $26.2 \%$ and $16.9 \%$ respectively. This showed that premalignant cervical lesion was more prevalent among HIV-positive women though not statistically significant $(P=0.201)$. However, using risk ratio (RR), the risk of developing cervical lesions is 1.55 times more in HIV exposed women than HIV negative women.

Conclusion: There is therefore need for the Physicians to use every opportunity to counsel their clients on the need for routine cervical cancer screening especially in adult HIV clinics.
\end{abstract}

Keywords: HIV-positive women; Papanicoleau smear; premalignant cervical lesions; prevalence.

\section{INTRODUCTION}

HIV infection is associated with an increased risk of diverse cancers and has emerged as a single major factor in the recent accelerated burden of cancer in Sub-Saharan Africa [1]. It is the best example of the close relationship between infection, immune dysfunction and evolution of malignancies. Classically, the Centers for Disease Control and Prevention (CDC) designated Kaposi sarcoma (KS), cervical cancer (CC) and non-Hodgkin's lymphoma (NHL) as AIDS defining cancers (ADCs) because of the association of these cancers with increased risk of HIV infection [2]. Of the three cancers, only cervical cancer can be screened for. According to a 2012 report on two major cancer registries in Nigeria, cervical cancer is the most common cancer among women in the most of sub Saharan Africa. However in Nigeria, it is the second most common after breast cancer. The findings are also somewhat similar to the 2008 GLOBOCAN estimates for the whole co untry of 32.9 per 100000 for the period 1998 to 2002. This suggests that the incidence of cervical cancer has remained largely stable over time. This seemingly stable incidence of cervical cancer over time could possibly be due to poor screening coverage in Nigeria. In Nigeria Pap smear is not a scheduled routine programme, hence most women pay out of pocket to get it done. Only a very small percentage of women are currently on National Health Insurance Scheme [3].

Cervical cancer is also the second most common malignancy in women worldwide, second only to breast cancer; and it remains a leading cause of cancer-related deaths for women in developing countries [4]. Women with HIV/AIDS are at a greater risk of developing cervical intraepithelial neoplasia $(\mathrm{CIN})$ which is a precancerous lesion that often precedes the development of cancer of the cervix. CIN occurs in about $20 \%$ of women with HIV/AIDS, and may be associated with Human papilloma virus (HPV) infection as compared to $4 \%$ in HIV Negative women [5]. In addition, high-grade $\mathrm{CIN}$ can progress to invasive cervical cancer, and women with AIDS are therefore at higher risk of developing this cancer.

CIN is common in HIV infected women because both HIV and HPV are sexually transmitted, HIV infected women are more likely to have persistent HPV infection and Persistent infection with one or more oncogenic HPV subtypes is a major factor in the pathogenesis of premalignant and malignant cervical disease [6]. Many studies worldwide have shown a higher prevalence of cervical intraepithelial neoplasia (CIN) among HIV-positive women than among HIV-negative women. In the HIV Epidemiology Research Study (HERS, a US observational, multisite cohort study) one of the larger studies of HIVpositive women, CIN was present in $19 \%$ of HIVpositive women and only in $5 \%$ of the HIVnegative women. Similar results were found from the Women's Interagency HIV Study Group (WIHS) and from a large study of women in Abidjan, Ivory Coast [7]. Also, in a study done at the Lagos University Teaching Hospital (LUTH), Prevalence of squamous intraepithelial lesion (SIL) was higher in those who were HIV positive than in those who were HIV negative, $10.9 \%$ vs $4.3 \%(p=0.00798)$. Prevalence of high grade SIL was higher in HIV positive than HIV negative subjects, $7.9 \%$ vs $2.6 \%(p=0.0115)$ [8]. 
Despite the high mortality from cervical cancer in developing countries, these morbidity and mortality could be greatly reduced using preventive health methods such as safe sexual practice and early detection of the disease through the Papanicolaou (Pap) smear test. The Pap smear test is currently the most widely used approach for preventing progression of cervical cancer, and is considered the best approach to reduce cervical cancer incidence worldwide [9] it is however surprising that the level of awareness of cervical cancer and its screening is below average in Nigeria. This might be because traditionally in Nigeria the there is no standardardized routine Pap smear screening programme put in place for women. Most women need to pay out of pocket to get the Pap smear done as less than $10 \%$ of Nigerians are currently on NHS In a cross sectional survey done at the university of Nigeria Teaching Hospital, it was reported that ninety $(30 \%)$ respondents were aware of cervical cancer. This included 33 (22.0\%) HIV-positive women and 57 (38\%) HIVnegative women. Twenty-nine $(87.9 \%)$ women from the study group who were aware of cervical cancer did not know their risks of developing the illness, while the remaining $4(12.1 \%)$ thought that their risk was the same as that in the general population. For the HIV-negative women, 43 $(75.4 \%)$ had no idea of their risk, $10(17.5 \%)$ thought it was same as in the general population, and $4(7.0 \%)$ felt that their risk was reduced [10]. It is obvious from their study that HIV positive women have low level of awareness and knowledge of risk factors for cervical cancer.

This study therefore aimed at assessing the level of awareness, current usage of pap smear test and prevalence of premalignant cervical lesion among HIV positive women.

\section{METHODOLOGY}

The study was conducted in the HIV clinic and the General Outpatient (GOP) clinic of the Federal Teaching Hospital, Ido-Ekiti (FETHI). It was a comparative cross sectional study which was carried out over a period of three months (May, June and September 2015).

The study population consisted of HIV positive women receiving care at the HIV clinic of FETHI, and comparatively matched against HIV negative women attending the GOP clinic of the same hospital. The sample size was calculated based on the national prevalence rate of HIV which was $4.1 \%$ as at 2012, [11] using the formula $n=z^{2} p q / d^{2}$. With an attrition rate of $10 \%$, the minimum sample size was 63 , which was rounded up to 65 . So 65 consenting HIV patients were used for the study. Similarly 65 consenting HIV negative women attending the GOP clinic of FETHI was used as control.

Systematic random sampling of consenting HIV positive women who have been attending clinic and were seen during the study period was used for the study. The inclusion criteria were consenting HIV positive women ages 18 to 65 years who were sexually active and consenting HIV negative women of same age range while the exclusion criteria were Pregnant HIV positive women for medico legal reason, severely ill patients and patients with clinical features suggestive of sexually transmitted infections as at the study period because the vagina discharge might interfere with the sample collection and the result. Women who had previously been treated for cervical neoplasia/cancer or had had total hysterectomy or were menstruating at time of the study enrolment were also excluded because the sample taken would contain many red blood cells which would amber cytology evaluation.

A semi-structured interviewer administered questionnaire was administered to both the HIV positive and HIV negative women to determine the risk factors for development of premalignant lesions. Both were also screened for premalignant lesions with Pap smear test. The specimens were sent to the histopathology department of FETHI for cytology and the results were categorized as normal, ASCUS (Atypical squamous cell of undetermined significance), AGUS (Atypical glandular cell of undetermined significance), LSIL (Low-grade squamous intraepithelial lesion), HSIL (High-grade squamous intraepithelial lesion) or cancer. Participants whose samples were positive for premalignant cervical lesions were informed, counseled and referred to the gynaecologist for expert management.

Ethical clearance was obtained from the ethical committee of FETHI. Informed consent (verbal and written) was obtained from willing participants. The participants were assured of confidentiality and also that their participation were voluntary. 
Data were analyzed using SPSS version 19. Statistics such as mean, mode, median and standard deviation were determined. Association between dependent and independent variables were compared using Pearson's chi square and Fischer exact test as appropriate. The level of statistical significance is taken as $\mathrm{P} \leq$ 0.05 .

\section{RESULTS}

A total of 130 respondents (65 each for study and control groups) who fulfilled the inclusion criteria and were recruited from the HIV and GOP clinics over 12 weeks were studied. They were aged between 21 and 65 years [mean $40.98 \pm 10.68$ years].

Table 1 the mean age of both groups were within same range (study group 39.73, control group 40.98). The control group had more respondents with tertiary education (64.6\% vs $41.5 \%)$. The study group had no professionals as against the control group with $16.9 \%$ of the respondents being professionals. Majority of the respondents in both groups were married $(84.6 \%$ and $92.3 \%$ ), more than half of the respondents $(52.5 \%)$ in the study group had been married for $10-20$ years and both groups had $\geq 4$ children (35.4\%).

Table 1. Comparison of socio-demographic characteristics between the study and control groups

\begin{tabular}{|c|c|c|c|c|c|}
\hline \multirow[t]{2}{*}{ Variables } & \multicolumn{2}{|c|}{ Subject category } & \multirow[t]{2}{*}{$x^{2}$} & \multirow[t]{2}{*}{ df } & \multirow[t]{2}{*}{$P$ value } \\
\hline & Study & Controls & & & \\
\hline \multicolumn{6}{|l|}{ Age (years) } \\
\hline $21-30$ & $11(16.9)$ & $9(13.9)$ & & & \\
\hline $31-40$ & $28(43.1)$ & $29(44.6)$ & 0.265 & 3 & 0.966 \\
\hline $41-50$ & $16(24.6)$ & $16(24.6)$ & & & \\
\hline$>50$ & $10(15.4)$ & $11(16.9)$ & & & \\
\hline Mean \pm SD & $39.73 \pm 8.57$ & $40.98 \pm 10.68$ & -0.736 & 128 & $0.463^{*}$ \\
\hline \multicolumn{6}{|l|}{ Religion } \\
\hline Christianity & $57(87.7)$ & $59(90.8)$ & & & \\
\hline Islam & $7(10.8)$ & $6(9.2)$ & & & $0.778^{\star \star}$ \\
\hline Others & $1(1.5)$ & $0(0.0)$ & & & \\
\hline \multicolumn{6}{|l|}{ Educational status } \\
\hline Primary & $20(30.8)$ & $13(20.0)$ & & & \\
\hline Secondary & $18(27.7)$ & $8(12.3)$ & & & \\
\hline Tertiary & $27(41.5)$ & $42(64.6)$ & & & $0.010^{n}$ \\
\hline No education & $0(0.0)$ & $2(3.1)$ & & & \\
\hline \multicolumn{6}{|l|}{ Occupation } \\
\hline Professionals & $0(0.0)$ & $11(16.9)$ & & & \\
\hline C/S, Teachers & $18(28.1)$ & $28(43.1)$ & & & \\
\hline Traders, Artisans & 39 (60.9) & $23(35.4)$ & & & $0.001^{* *}$ \\
\hline Farmers & $2(3.1)$ & $2(3.1)$ & & & \\
\hline Students & $5(7.8)$ & $1(1.5)$ & & & \\
\hline \multicolumn{6}{|l|}{ Marital status } \\
\hline Single & $6(9.2)$ & $3(4.6)$ & & & \\
\hline Married & $55(84.6)$ & $60(92.3)$ & & & $0.411^{\star *}$ \\
\hline Separated / Divorced & $4(6.2)$ & $2(3.1)$ & & & \\
\hline \multicolumn{6}{|c|}{ Duration of marriage (years) } \\
\hline$>10$ & $43(72.8)$ & $39(62.9)$ & 1.378 & 2 & 0.240 \\
\hline$\leq 10$ & $16(27.2)$ & $23(37.1)$ & & & \\
\hline \multicolumn{6}{|l|}{ Number of children } \\
\hline$<4$ & $42(64.6)$ & $42(64.6)$ & 0.336 & 2 & 0.854 \\
\hline$\geq 4$ & $23(35.4)$ & $23(35.4)$ & & & \\
\hline
\end{tabular}


Table 2 shows that only $4.6 \%$ of the study group and $12.3 \%$ of the control group had ever done Pap smear. Of the respondents who had done Pap test, $33.3 \%$ of the study group had done $50 \%$ of the control group had done it more than once.

In Table 3, abnormal cervical lesions were present in $26.2 \%$ of the study group while it was present in $16.9 \%$ of the control group. This was not statistically significant with a p-value of 0.201 . However, using risk ratio (RR), the risk of developing cervical lesions is 1.55 times more in HIV exposed women than HIV negative women.
Table 4 shows the pattern of abnormal cytology among the study and the control group. Though the HGSIL is higher among the HIV positive participants but this is not statistically significant.

In Table 5, none of the 3 respondents from the study group who had ever done pap smear had abnormal cervical cytology while $17(27.4 \%)$ of those who had never done pap smear had abnormal cervical cytology. Of the 8 respondents from the control group who had had pap smear, $3(37.5 \%)$ had abnormal cervical cytology.

Table 2. Usage of Pap smear among study subjects

\begin{tabular}{|c|c|c|c|}
\hline \multirow[t]{2}{*}{ Variables } & \multicolumn{2}{|c|}{ Subject category } & \multirow[t]{2}{*}{ Fisher's exact $P$} \\
\hline & Study & Controls & \\
\hline \multicolumn{4}{|c|}{ Ever done Pap smear } \\
\hline Yes & $3(4.6)$ & $8(12.3)$ & 0.206 \\
\hline No & $62(95.4)$ & $57(87.7)$ & \\
\hline \multicolumn{4}{|c|}{ Number of Pap smear ever done } \\
\hline One & $2(66.7)$ & $4(50.0)$ & 0.152 \\
\hline Two & $0(0.0)$ & $4(50.0)$ & \\
\hline Three & $1(33.3)$ & $0(0.0)$ & \\
\hline
\end{tabular}

Table 3. Cytology results

\begin{tabular}{|c|c|c|c|c|c|c|}
\hline Cytology & Study & Control & $x^{2}$ & $P$ value & RR & $\mathbf{C l}$ \\
\hline Abnormal & $17(26.2)$ & $11(16.7)$ & 1.639 & 0.201 & 1.545 & $0.786-3.038$ \\
\hline Normal & $48(73.8)$ & $54(83.1)$ & & & & \\
\hline
\end{tabular}

Table 4. Pattern of abnormal cytology result

\begin{tabular}{lllll}
\hline Cytology results & Study group & Control group & $\mathbf{X}^{2}$ & P-value \\
\hline HGSIL & 4 & 1 & & \\
LGSIL & 8 & 6 & 0.139 & 0.709 \\
AGUS & 2 & 2 & & \\
ASCUS & 3 & 2 & & \\
\hline
\end{tabular}

Table 5. Relationship between usage of Pap smear test and development of pre-malignant cervical lesions among the study group and controls

\begin{tabular}{|c|c|c|c|c|c|c|}
\hline \multirow[t]{2}{*}{ Variables } & \multicolumn{2}{|c|}{$\begin{array}{l}\text { Premalignant cervical } \\
\text { lesion (cytology) } \\
\text { study group }\end{array}$} & & \multicolumn{2}{|c|}{$\begin{array}{l}\text { Premalignant cervical } \\
\text { lesion (cytology) } \\
\text { control group }\end{array}$} & \\
\hline & Abnormal & Normal & & Abnormal & Normal & \\
\hline \multicolumn{7}{|c|}{ Ever done Pap smear } \\
\hline Yes & $0(0.0)$ & $3(100.0)$ & $3(100.0)$ & $3(37.5)$ & $5(62.5)$ & ..0) \\
\hline No & $17(27.4)$ & $45(72.6)$ & $62(100.0)$ & $8(14.0)$ & $49(86.0)$ & $57(100.0)$ \\
\hline & \multicolumn{3}{|c|}{ Fisher's exact $P=0.561$} & \multicolumn{3}{|c|}{ Fisher's exact $P=0.126$} \\
\hline
\end{tabular}




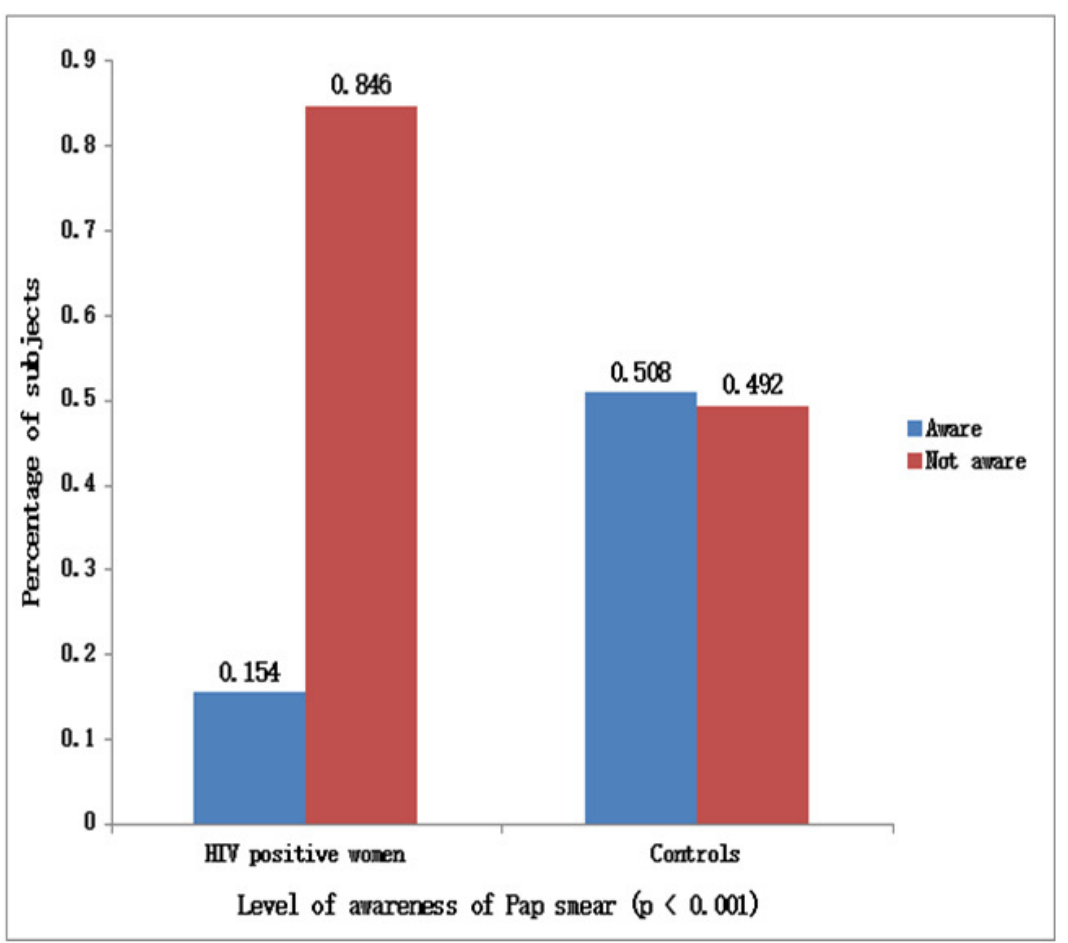

Fig. 1. Clustered bar chart showing that the HIV positive women were significantly less likely to be aware of cervical screening tests compared to the control subjects

\section{DISCUSSION}

This comparative cross sectional study has determined the relationship between cervical cancer screening awareness and development of premalignant cervical lesions among HIV positive women attending HIV clinic in FETHI, Ido-Ekiti, in the South-Western Nigeria.

\subsection{Socio-demographic Characteristics of Respondents}

The modal age group was $31-40$ years and the mean age was $39.7 \pm 8.5$ and $41.0 \pm 10.6$ years for the study and control group respectively. This was consistent with a study done in Abuja by Ononogbu et al. [12] where the mean age of respondent was 35 years. Similarly, a study done in Kenya by Memiah et al. showed a median age of 40 years amongst women receiving care in a resource constraint setting which is consistent with most other studies around the globe [13-15]. This could be attributable to the fact that most women are recruited into HIV care through PMTCT programme, thereby leaving out the younger age group and the older ones. Majority of the respondents in both the study $(41.5 \%)$ and control group (64.6\%) had tertiary level of education, however the control group had higher educational status, which was statistically significant $(p=0.010)$. This is not surprising as poverty and ignorance are factors responsible for high prevalence of HIV in Nigeria due to low access to information and education about HIV/AIDS and women with higher educational status are more prone to this information and therefore more likely to practice safer sex. This finding is consistent with related studies in SouthEastern and Northern Nigeria [16,17]. The impact of education was evident in this study as it might account for the observed significant differences in the awareness of cervical cancer and Pap test between the study group and the control group. This is an important advantage of women empowerment.

\subsection{Current Usage of Pap smear among Respondents}

Only $3(4.6 \%)$ of the study group had ever had Pap smear while $8(12.3 \%)$ of the control group had ever had pap smear. Of the three respondents in the study group who have had pap smear, $1(33.3 \%)$ has done it thrice while the other $2(66.7 \%)$ had done it once. Ezechi et al. got control group a higher prevalence, 9.4\%, 
amongst HIV positive women in Lagos [18]. Ezem found that only $7.1 \%$ of women in Owerri had ever done pap smear, which is less than that found among the respondents in this study [19]. Studies around the country have shown very low usage of pap smears test. Owoeye and Ibrahim found that $12.1 \%$ of their respondents have had pap smear test while Wright et al. in Lagos found $8.5 \%$ among their respondents [20,21]. These low uptake found in different studies could have been linked to the low level of awareness of cervical cancer screening test among these respondents, however, despite the high level of awareness shown by Owoeye and Ibrahim the uptake of cervical cancer screening test was still very low [20]. Similarly, Gharoro and Ikeanyi also found a high cervical cancer and pap smear awareness (65\% and $64 \%$ ) but the uptake rate was very low (14.1\%) among the respondents [22]. This shows that awareness will not necessarily translate to usage if there is no provision of a national screening programme, especially for high risk groups like the HIV positive women. In developed countries where there are standard programmes for cervical cancer screening, awareness and uptake are very high. In a study done in Catalonia, Spain among HIV positive women, screening coverage was found to be $60.0 \%$ and the researchers considered this as low screening coverage in their study [23]. In the study done by Ezem in Owerri, reasons ranging from unawareness, being unnecessary, fear of detection of cancer and anxiety were given as reasons for not doing the test [19]. Fear and anxiety stems from poor understanding of the rationale behind cervical screening. Similarly, in a study done by Ndikom and Ofi among women in lbadan, lack of awareness, illiteracy, nonchalant attitude to health and financial constraints were factors identified to affect uptake of cervical cancer screening among the respondents [24]. These reasons were however contrary in a study done among female nurses in Nnewi, where the rate of uptake was found to be $5.7 \%$ with majority of the respondents $(37.1 \%)$ having no reason for not undergoing pap smear, $25 \%$ felt they were not candidate for cervical cancer while 15\% gave fear of outcome as their reason [25]. This shows that even among health workers where awareness is high uptake of cervical cancer screening is very low, therefore health workers especially females who should be at the forefront of this awareness campaign should be properly educated again that the benefit of early detection is the probability of a total cure.

\subsection{Prevalence of Premalignant Cervical Lesions among Respondents}

Recent guidelines recommend that, following two initial normal Pap-smears at a 6-month interval, all HIV-positive women should undergo annual cervical cytologic examination. In addition, it is recommended that all immunosuppressed women with atypical squamous cells undergo colposcopy [26]. Out of the 65 HIV positive women screened for premalignant cervical lesions, 17 (26.2\%) had abnormal cytology result which is higher than 11 (16.9\%) among the control group though this was not statistically significant. This prevalence is higher than $12.6 \%$ and $4.6 \%$ found by Dim et al. [27] among HIV positive and HIV negative women respectively. Ezechi et al. [28] also found a similar prevalence with Dim, $14.3 \%$ and $3.3 \%$ among HIV positive and negative women respectively. Anorlu et al. [8] also got a similar prevalence of $10.9 \%$ and 4.3\% among HIV positives and negatives respectively. However, Bassey et al. [29] in Port Harcourt found a higher prevalence of $34.4 \%$ and $19.8 \%$ among HIV positive and HIV negative women respectively. The differences encountered in these studies might be due to the prevalence of HPV infection and level of immune suppression. The difference in the prevalence of abnormal cytology between the two groups in this study is consistent with the findings in other studies and supports the fact that compared with HIV negative women, HIV positive women are at greater risk of developing abnormal cervical cytology. A Brazilian study also found a high prevalence of CIN among HIV positive women to be $23.6 \%$ which is similar to the findings in this study [30]. Moodley et al. [14] found a prevalence of $66 \%$ of cervical abnormalities among HIV positive women initiating HAART in South Africa. This is much higher than most studies in Africa and even in developed countries. However, the high prevalence was attributed to the low immune status of their respondents.

\section{CONCLUSION}

There was higher rate of cervical premalignant lesion found among HIV positive patients when compared with HIV negative women. In spite of this higher risk, the rate of uptake of Papanicoleau smear was abysmally low among HIV positive women. There is need for healthcare providers to be proactive in educating women on regular cervical cancer screening and structured screening programme should be put in place. 


\section{CONSENT}

As per international standard or university standard, patient's written consent has been collected and preserved by the authors.

\section{ETHICAL APPROVAL}

As per international standard or university standard, written approval of Ethics committee has been collected and preserved by the authors.

\section{COMPETING INTERESTS}

Authors have declared that no competing interests exist.

\section{REFERENCES}

1. Mbulaiteye SM, Katabira ET, Wabinga $\mathrm{H}$, Parkin DM, Virgo $P$, Ochai $R$, et al. Spectrum of cancers among HIV-infected persons in Africa: The Uganda AIDScancer registry match study. Int $\mathrm{J}$ Cancer. 2006;118:985-990.

2. Akarolo-Anthony SN, Maso LD, Igbinoba F, Mbulaiteye SM, Adebamowo CA. Cancer burden among HIV-positive persons in Nigeria: Preliminary findings from the Nigerian AIDS-cancer match study. Infectious Agents and Cancer. 2014; 9:1.

DOI: 10.1186/1750-9378-9-1

Available:http://www.infectagentscancer.co $\mathrm{m} /$ content $/ 9 / 1 / 1$

3. JedyAgba E, Curado MP, Ogunbiyi O, Oga E, Fabowale T, Igbinoba F, Osubor G, Otu $\mathrm{T}$, Kumai H, Koechlin A, Osinubi P. Cancer incidence in Nigeria: A report from population-based cancer registries. Cancer Epidemiology. 2012;36(5):e271-8. -146.

4. Abdul-Salam AA, Ogunnorin OB, AbdulSalam RA. HIV seroprevalence in patients with Carcinoma of the cervix in lbadan, Nigeria. Ghana Med J. 2008;42(4):141143.

5. Wright TC, Ellerbrock TV, Chiasson MA, Van Devanter N, Sun XW. Cervical intraepithelial neoplasia in women infected with human immunodeficiency virus: Prevalence, risk factors, and validity of Papanicolaou smears. New York Cervical Disease Study. Obstet Gynecol. 1994; 84(4):591-597.

6. Franceschi $S$, Jaffe $H$. Cervical cancer screening of women living with HIV infection: A must in the Era of antiretroviral therapy. Clin Infect Dis. 2007;45(4):510513.

7. Lesley O. Cervical cancer in women with HIV. HIV and AIDS Treatment in Practice; 2011.

Available:www.aidsmap.com

(Accessed February 11, 2013)

8. Anorlu RI, Igwilo $\mathrm{Cl}$, Akanmu AS, Banjo $A A$, Odunukwe NN, Okany CC, et al. Prevalence of abnormal cervical smears among patients with HIV in Lagos, Nigeria. West Afr J Med. 2007;26(2):143-147.

9. Hyacinth HI, Adekeye OA, Ibeh JN, Osoba T. Cervical cancer and pap smear awareness and utilization of pap smear test among federal civil servants in North Central Nigeria. PLoS ONE. 2012;7(10): e46583.

10. Dim CC. Cervical cancer screening among HIV positive women in Enugu, Nigeria: $6^{\text {th }}$ EDCTP Forum, Addis-Ababa, Ethiopia, $11^{\text {th }}$ October; 2011.

Available:www.edctp.org/EDCTP

11. National agency for the control of AIDS, Nigeria 2012 GARPR.

Available:naca.gov.ng

(Accessed Mar 2013)

12. Ononogbu $U$, Almujtaba M, Modibo $\mathrm{F}$, Lawal I, Offiong R, Olaniyan $\mathrm{O}$, et al. Cervical cancer risk factors among HIVinfected Nigerian women. BMC Public Health. 2013;13:582.

13. Memiah P, Mbuthia W, Kiiru G, Agbor S, Odhiambo F, Ojoo S, et al. Prevalence and risk factors associated with precancerous cervical cancer lesions among HIVinfected women in resource-limited settings. AIDS Research and Treatment. 2012;1-7.

14. Moodley JR, Constant D, Hoffman M, Salimo A, Bruce A, Rybicki E, et al. Human Papillomavirus prevalence, viral load and precancerous lesions of the cervix in women initiating highly active retroviral therapy in South Africa: A cross sectional study. BMC Cancer. 2009;9(1): 275.

15. Gedefaw A, Astatkie A, Tessema GA. The prevalence of precancerous cervical cancer lesion among HIV-infected women in Southern Ethiopia: A cross-sectional study. PLoS ONE. 2013;8(12):e84519. DOI: 10.1371/journal.pone.0084519

16. Sulaiman BU, Omolara KA, Sunday SO, Mohammed SS. Cervical cytopathology pattern among HIV seropositive and HIV 
seronegative women in Zaria. The Internet Journal of Gyneacology and Obstetrics. 2014;18:1.

17. Dim CC, Dim NR, Ezegwiu HU. An unmet cancer screening need of HIV-positive women in Southeastern Nigeria. Medscape J Med. 2009;11(1):19.

18. Ezechi OC, Gab-Okafor CV, Ostergren $\mathrm{PO}$, Pettersson KO. Willingness and acceptability of cervical cancer screening among HIV positive Nigerian women. BMC Public Health. 2013;13:46.

19. Ezem BU. Awareness and uptake of cervical cancer screening in Owerri, SouthEastern Nigeria. Ann Afr Med. 2007;6:948.

20. Owoeye IOG, Ibrahim IA. Knowledge and Attitude towards cervical cancer screening among female students and staff in a tertiary institution in Niger Delta. International Journal of Medicine and Biomedical Research. 2013;2(1):48-56.

21. Wright $\mathrm{KO}$, Aiyedehin O, Akinyinka MR, llozumba O. Cervical cancer: Community perception and preventive practices in an urban neighborhood of Lagos (Nigeria). ISRN Preventive Medicine. 2014;2014: 950534.

DOI: $10.1155 / 2014 / 950534$

22. Gharoro EP, Ikeanyi EN. An appraisal of the level of awareness and utilization of the Pap smear as a cervical cancer screening test among female health workers in a tertiary health institution. Int $\mathrm{J}$ Gynecol Cancer. 2006;16(3):1063-8.

23. Valeria S, Cristina A, Jordi C. Low prevalence of cervical cancer screening among HIV-positive women in Catalonia, Spain. J AIDS Clinic Res; 2013.

24. Ndikom CM, Ofi BA. Awareness, perception and factors affecting utilization of cervical cancer screening services among women in Ibadan, Nigeria: A qualitative study. Reproductive Health. 2012;9:11.

25. Udigwe GO. Knowledge, attitude and practice of cervical cancer screening (Pap smear) among female nurses in Nnewi, Southeastern Nigeria. Nigerian Journal of Clinical Practice. 2006;9(1): 40-43.

26. IRIN Africa/Kenya: More cervical cancer screening for HIV positive patients urged. Available:http://www.irinnews.org/ (Assessed March $5^{\text {th }}$ 2013)

27. Dim CC, Ezegwui HU, Ikeme AC, Nwagha UI, Onyedum CC. Prevalence of cervical squamous intraepithelial lesions among HIV-positive women in Enugu, Southeastern Nigeria. Journal of Obstetrics and Gynaecology. 2011;31:759-762.

28. Ezechi OC, Pettersson KO, Okolo CA, Ujah IAO, Ostergren PO. The association between HIV infection, antiretroviral therapy and cervical Squamous Intraepithelial Lesions in South Western Nigerian Women. PLoS ONE. 2014;9(5): e97150.

DOI: 10.1371/journal.pone.0097150

29. Bassey G, Jeremiah I, Ikimalo JI, Fiebai PO, Athanasuis BP. Abnormal cervical cytology among HIV-positive women in Nigeria. International Journal of Gynaecology and Obstetrics. 2014;125: 103-106.

30. Teixeira NCP, Aruajo ACL, Correa CM, Lodi CT, Lima MIM, Carvalho NO, et al. Prevalence and risk factors for cervical intraepithelial Neoplasia among HIVinfected women. Braz J Infect Dis. 2012; $16: 2$.

(C) 2017 Omoragbon et al.; This is an Open Access article distributed under the terms of the Creative Commons Attribution License (http://creativecommons.org/licenses/by/4.0), which permits unrestricted use, distribution, and reproduction in any medium, provided the original work is properly cited. http://sciencedomain.org/review-history/19313 